\title{
ANALYSIS OF RUBBER FORMING PROCESS OF FIRE BARRIER FROM TITANIUM CP2 ALLOY FOR AW 139 HELICOPTER
}

\author{
Mariusz Krakowski ${ }^{1,2}$, Jarosław Bartnicki ${ }^{1}$ \\ 1 Department of Computer Modelling and Metal Forming Technologies, Mechanical Engineering Faculty, \\ Lublin University of Technology, 36 Nadbystrzycka Str., 20-618 Lublin, Poland, e-mail: j.bartnicki@pollub.pl \\ 2 The Communication Equipment Manufacturing „PZL-Świdnik” S.A., Lotników Polskich 1, 21-045 Świdnik, \\ Poland, e-mail: mariusz.krakowski.gm@gmail.com
}

Received: 2015.03.30

Accepted: 2015.05 .08

Published: 2015.06.01

\begin{abstract}
This paper presents conditions of forming products from titanium sheets by means of rubber stamping method. After introducing the issues connected with these elements manufacturing for aviation industry, considering standards and legal regulations, technological problems occurring during forming deep stiffening ribs. The results in the characteristic curvatures and distortion in the final products were generated in the process heterogeneous internal stress state. The Authors aimed at explaining and presenting of solutions limiting occurrence of chosen shape faults, which disqualify these products application in aviation industry. The proposed solutions significantly reduced the incidence of these unfavorable phenomena. The modified method of rubber stamping of firewall from titanium alloy CP-2 sheet was successfully implemented in manufacturing conditions of PZL Swidnik.
\end{abstract}

Keywords: titanium CP2, rubber forming.

\section{INTRODUCTION}

The forming process of sheet parts on hydraulic presses with rubber blanket has been applied in the industry for many years, being the most widely used in small series and unitary production such as aviation industry [1]. This is connected with relatively small costs of instrumentation. In classical approach to sheet parts stamping on hydraulic presses, production facilities use a device consisting of a punch and a die, which have to be ideally fitted and, because of that, ideally manufactured, hence, this instrumentation costs are very high and sometimes a small change of a part shape requires manufacturing of a completely new instrumentation. The stamping process on hydraulic presses with rubber blanket differs from classical stamping by means of a punch and die in that the role of the punch is played by a rubber blanket, which matches up to each die shape, hence, only a half of a classical instrument has to be made. Due to that fact this instrumenta- tion costs are incomparably lower as the punch matches every shape $[2,3]$.

The development of plastics technology allowed for replacing used rubbers with polymer materials as well as classical rubber blanket with elastomeric bag, in which liquid is forced in under high pressure.

Presses of this type are widely used in aviation industry due to lower instrumentation costs and fast tool replacement in comparison with stamping by means of the punch and die. One of the companies in aviation industry applying such presses for sheet drawpieces production is PZL Świdnik from Augusta Westland group.

\section{FIREWALL OF HELICOPTER AW139}

For building engine decks firewalls were used in a form of flat surfaces with stiffening element guaranteeing stability and rigidity in a form of stiffening ribs. The shape of the consid- 
ered stiffening was included in the factory standard obligatory for AW products, in which the stiffness depth was defined together with radii and permissible deviations from nominal values. The schema of the discussed firewall is shown in Figure 1.

The proposed part contains parts which are typical for this type of firewalls, that is on the plane stiffening elements were made, which have to guarantee rigidity and stability of the product without the necessity of connection with other stiffening elements.

\section{ANALYSIS OF THE FORMING PROCESS BY MEANS OF A FLEXIBLE TOOL}

Within the scope of forming by means of flexible tools in PZL Świdnik conditions, two hydraulic presses are presently used, one of them is equipped with a classical rubber blanket. A simplified schema of this forming method is shown in Figure 2, and a tunnel press for this operation is presented in Figure 3.

These machines are used for manufacturing of drawpieces, both from steel sheets and light al-

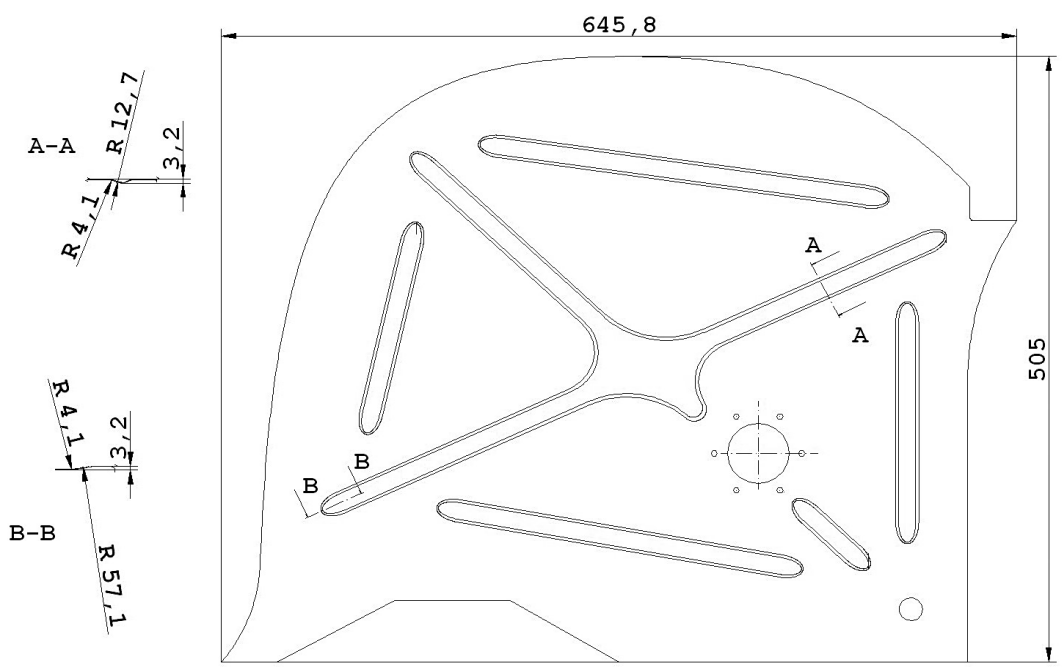

Fig. 1. Schema of firewall of helicopter AW139
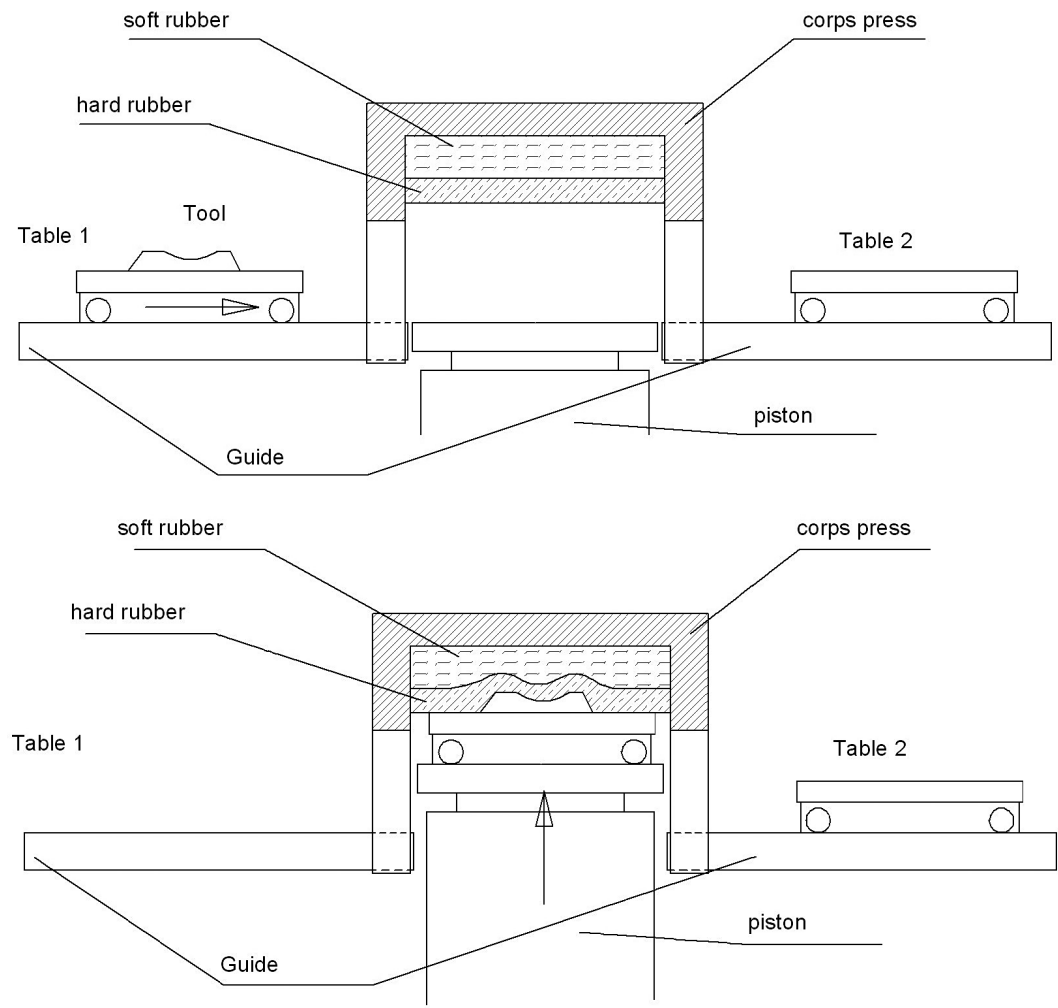

Fig. 2. Schema of rubber forming in the press with rubber blanket 


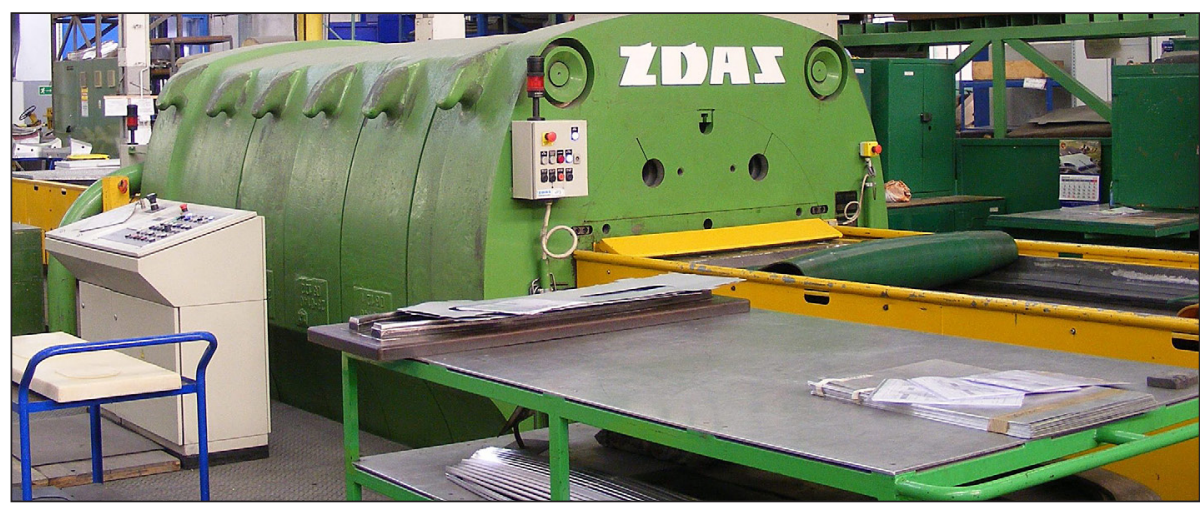

Fig. 3. The photo of a tunnel press

loys, such as aluminum and titanium alloys. The scope of manufactured drawpieces is as wide as different is diversity of helicopter parts, starting from brackets and reinforcement by carrying girders and longerons to titanium firewalls of engine decks.

Increasing safety [4] and qualitative requirements resulted in abandoning the previously used alloy 3.7024.1 according to the standard LN9297 and its replacement by CP-2 material according to the standard MIL-T-9046, of higher mechanical properties and larger resistance to higher temperatures. The change of this material caused difficulties connected with metal forming of firewalls with stiffening ribs. Making stiffening ribs of the assumed shape in walls and tolerances led to the presence of internal stresses in the material, which resulted in curvatures forming and appearance of characteristic surface folding, named distortions (Fig. 4).

High qualitative requirements applied in $\mathrm{Au}-$ gusta Westland do not permit the part usage for further machining in such a state. This issue imposed the survey of the production process. The initial analysis led to conclusions that during stamping the formed material, flowing to stiff-

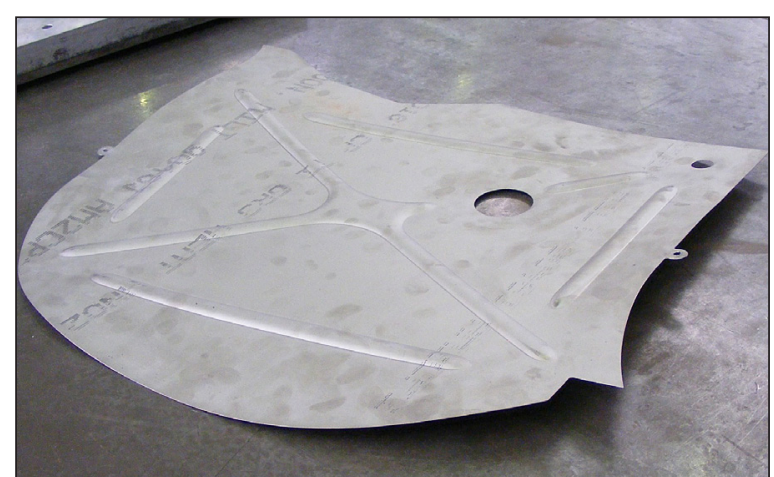

Fig. 4. Firewall from titanium alloy CP-2 with characteristic folding of the surface enings, caused stresses in the rest of the material, which cause drawpieces folding. One of the promising ideas is abandoning the previous approach, that is cutting off the part outline in development and deformation to the desired shape for stamping respectively larger material sheet on the device and, after this operation, outline cutting, which is presented in Figure 5.

In order to balance the force causing material flow, additional element, making balancing stresses, was introduced in the stiffening. For that reason, a device from machine lingoform, modified by addition of forming threshold retreated from the part outline and enlarged by building over to rectangular shape was used. For designing of the threshold shape around the outline, a simplified parts shape (cuttings were omitted and radii were enlarged) was assumed, and next, trimming line was retreated of constant value from the cutting simplified edge, which is visible in Figure 6.

After initial cutting of the material excess together with stamped stiffening element the drawpiece fulfilled qualitative requirements concerning stiffening ribs depth, and a considerable improvement of the quality in the plane area took place, unfortunately, not on the whole surface. The first tests brought a certain improvement of the formed element geometry. The results of these works are presented in Figure 7, where the product stamped in a sheet is shown.

A considerable improvement of quality of flat surfaces was observed in the influence areas of forming threshold running on curves. Unfortunately, in the areas in which forming threshold ran in straight lines, constant compression of stresses causing material folding took place. The observed phenomenon suggested the idea of constructing an instrument into forming threshold, running on curves and without straight lines. 

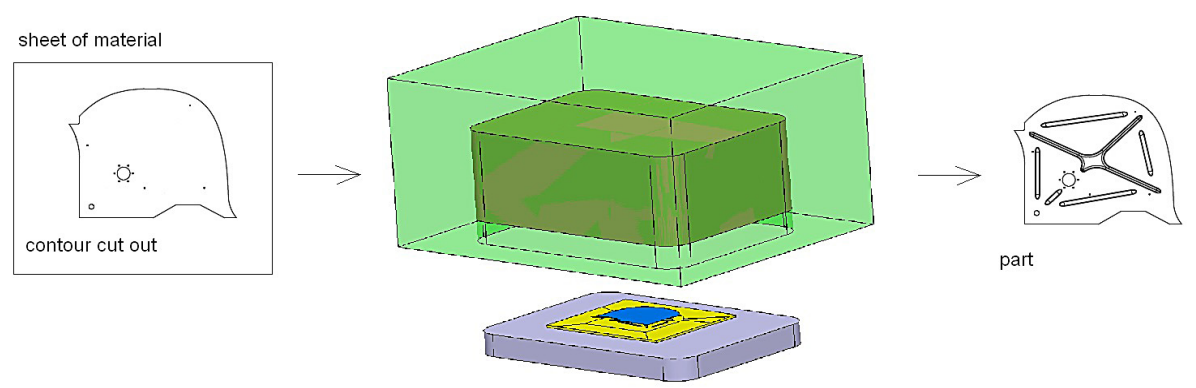

forming cut out blank on press
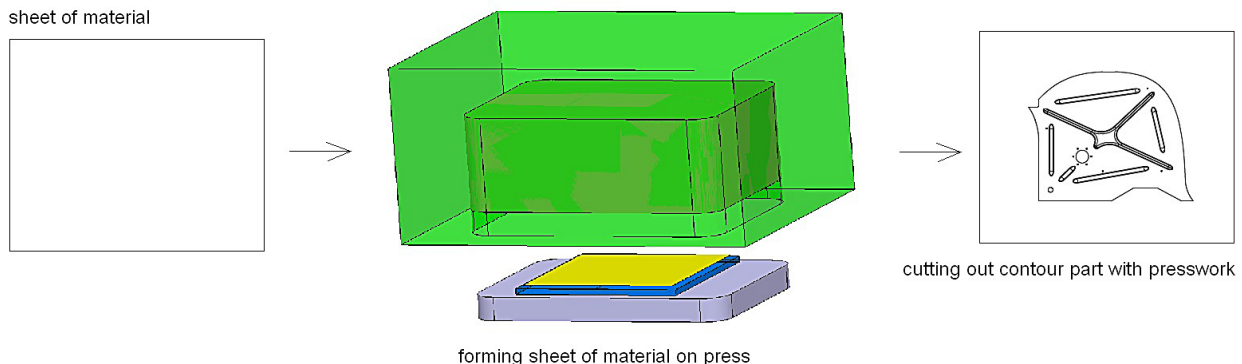

cutting out contour part with presswork

Fig. 5. Change of manufacturing schema of firewall drawpiece
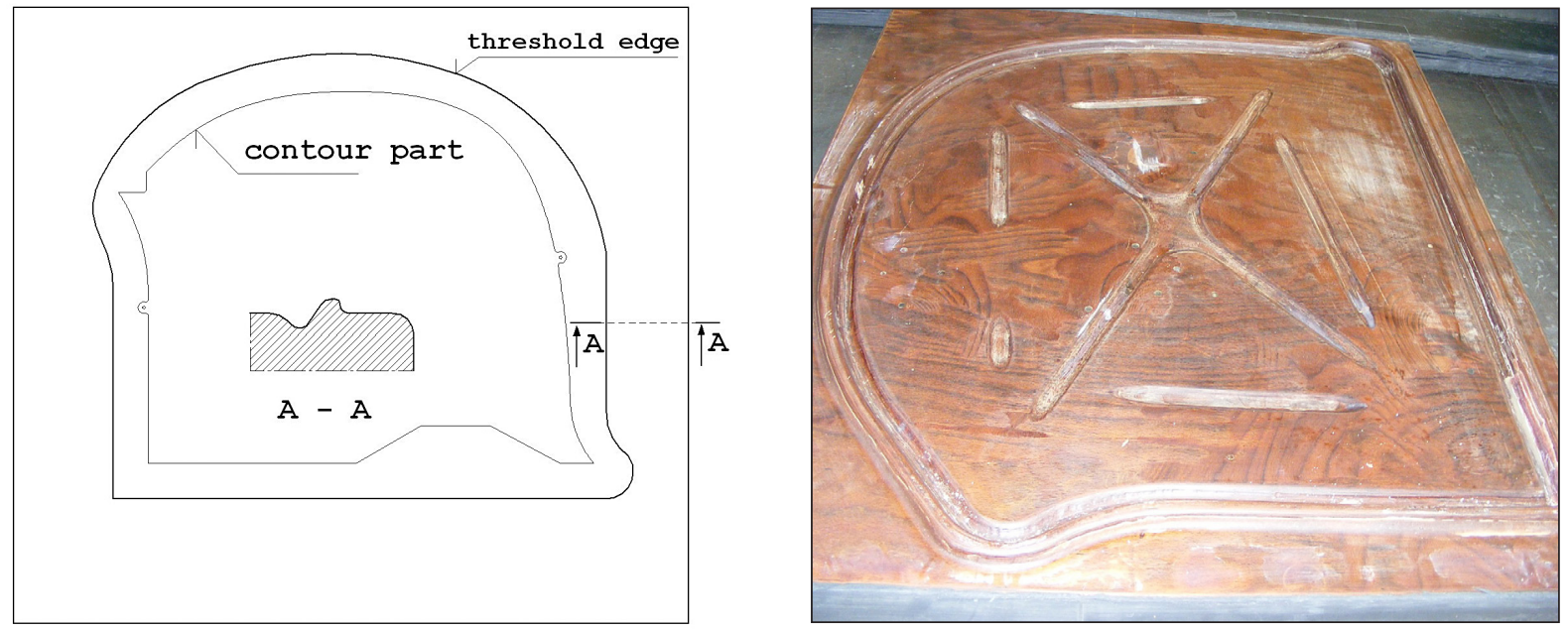

Fig. 6. Tool schema (on the left) and photo of the finished instrument (on the right)

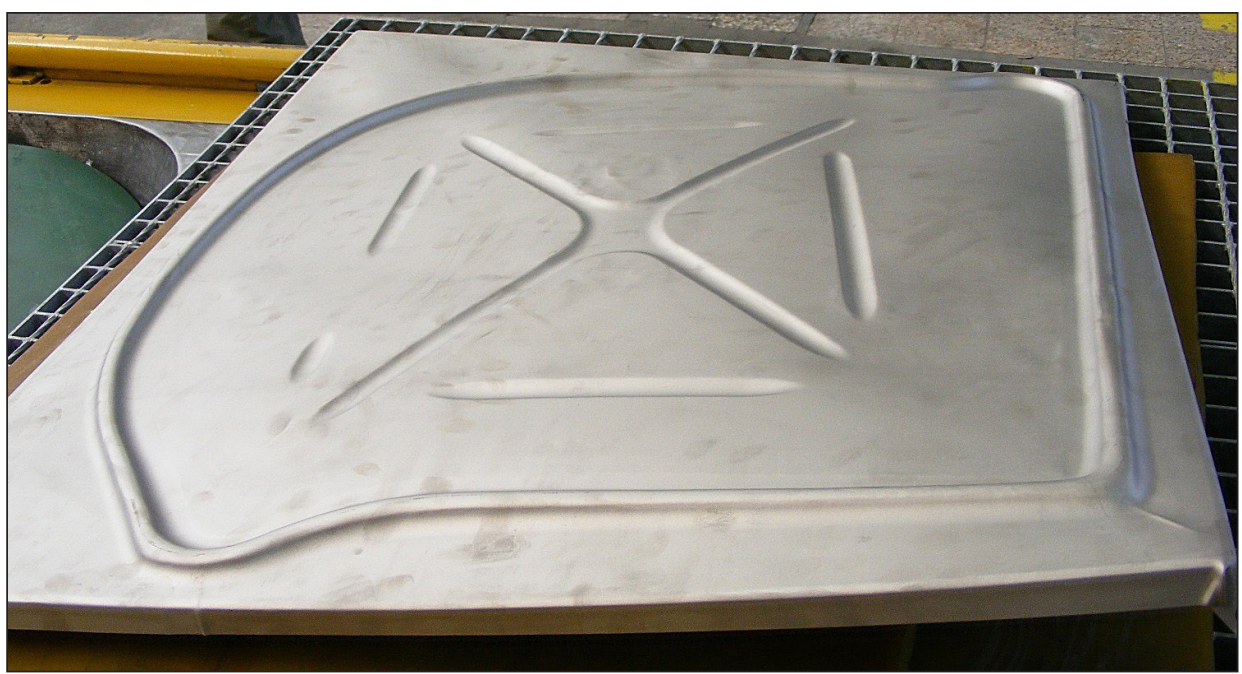

Fig. 7. Results of stamping tests from sheet 
This led to designing another tool modification, in which straight lines in the forming threshold geometry was replaced by curves. This solution is given in Figure 8, where the schema and photo of the finished tool are presented.

After stamping tests of the prepared material on the new instrument, a considerable improvement of surface quality was observed at obtaining required stiffening depth. In accordance with drawing requirements the depth was defined at $3.2 \mathrm{~mm}$ together with material depth equal $0.4 \mathrm{~mm}$ as it is presented in Figure 1 in sections A-A and B-B.

Considering requirements of the factory standard [5], the stamping depth should be between $2.55 \mathrm{~mm}$ to $3.05 \mathrm{~mm}$, and considering the material depth, it should be from 2.95 to 3.45 $\mathrm{mm}$. The manufactured drawpiece presented in Figure 9 shows a noticeable surface quality improvement in respect of deformations appearance in the plane area and elimination of surface folding phenomenon.

Application of simple short-time locksmith modifications allowed for obtaining acceptable adhesion of the part to the instrument shown in Figure 10.

The made drawpieces underwent measurement concerning stiffening depth. Measurements were made on 6 parts after 2 parts from following series. The areas of measurement are marked in Figure 11, yet their results are compared in the Table 1.

All obtained measurement results, for subsequent three series of finished products, remain within tolerance areas assumed in the factory standard [5]. This points to the rightness of the assumed solution of the technological problem and determine the further direction of works on sheet products with ribs forming.

\section{CONCLUSION}

Solution presented in the paper was successfully implemented in factory conditions of Augusta Westland in Świdnik. At present, the proposed method is used for manufacturing of the elements of firewalls type for helicopters
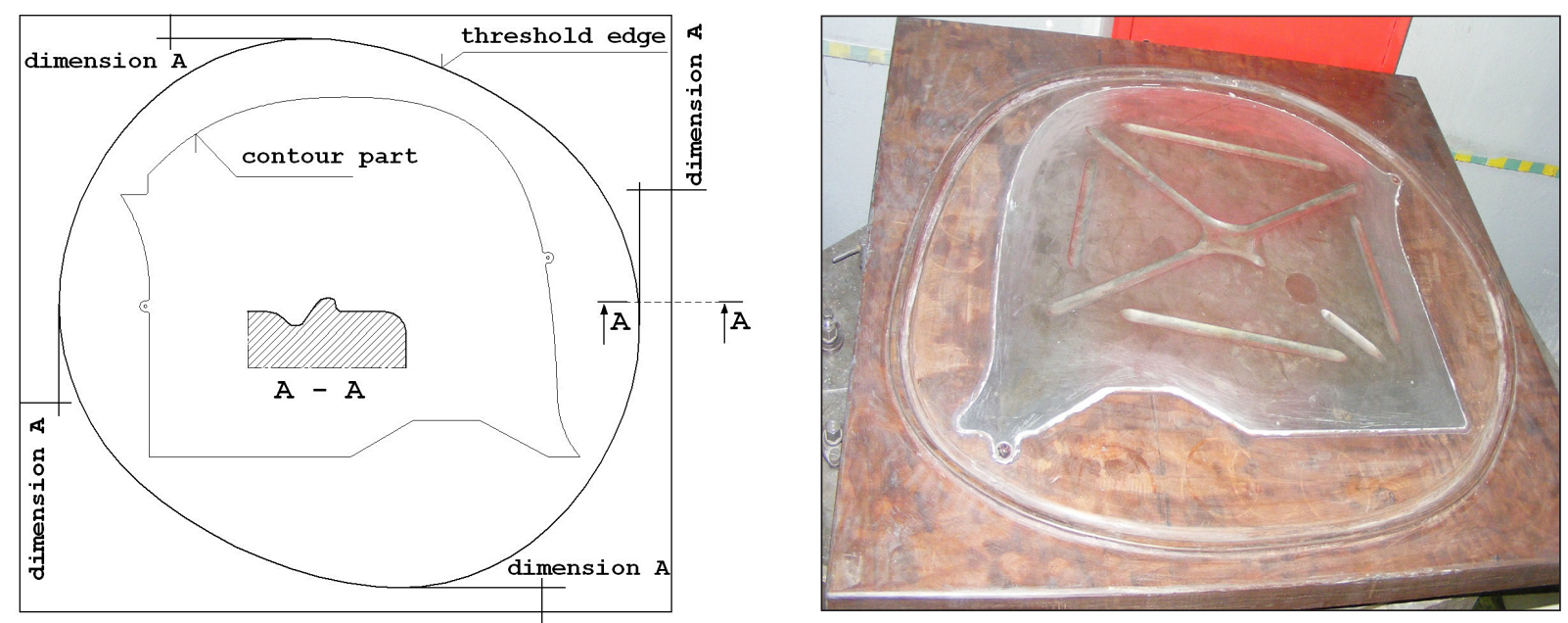

Fig. 8. Schema of the modified tool ( on the left) and photo of the finished instrument (on the right)
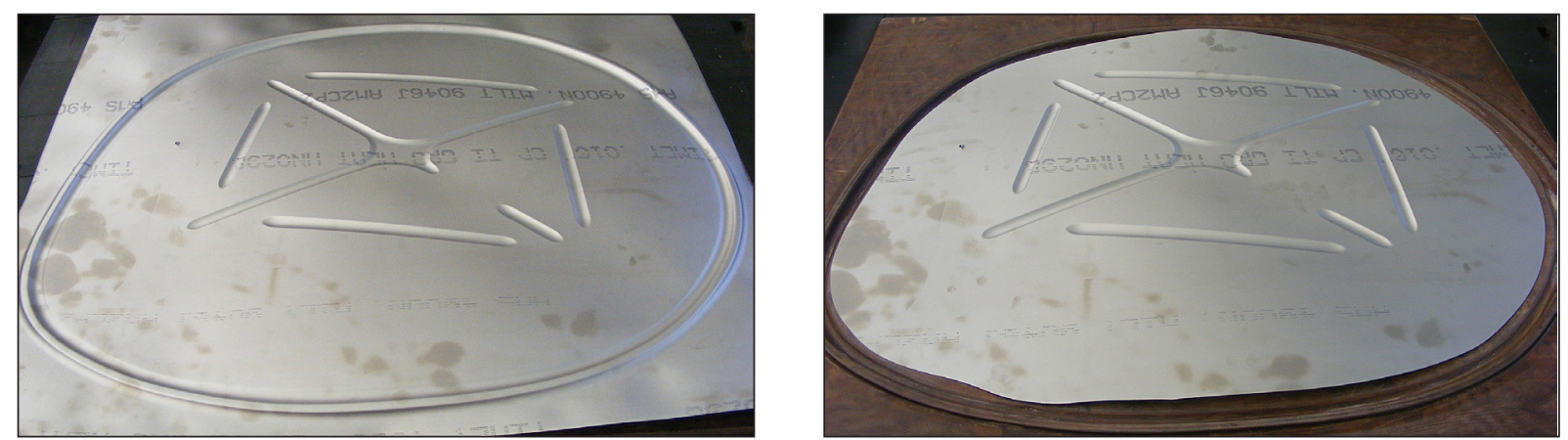

Fig. 9. Results of stamping tests from sheet in the modified tool 


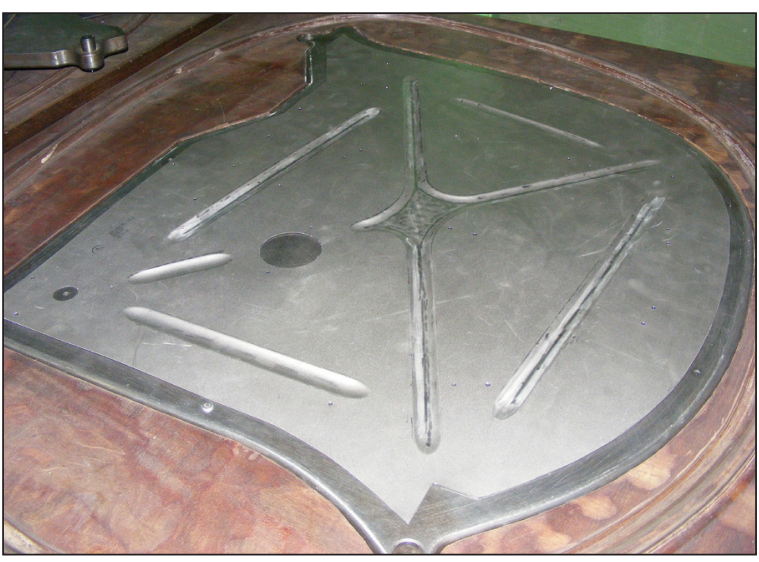

Fig. 10. Finished product in the form for geometry checking

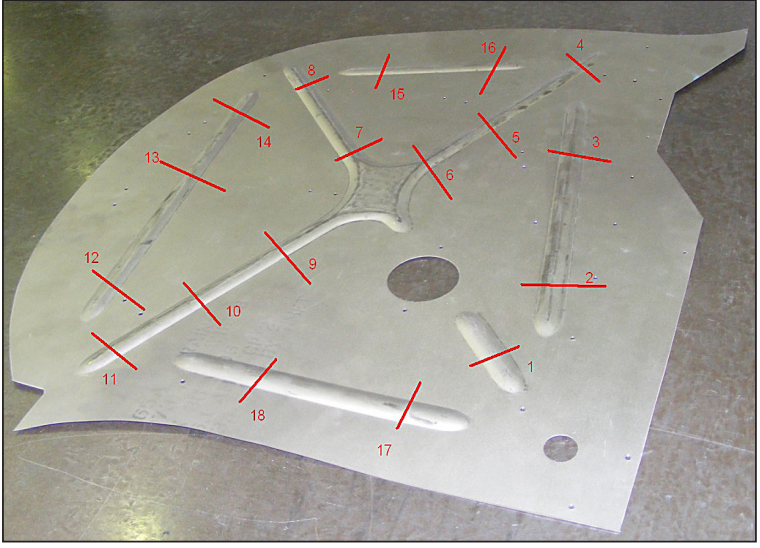

Fig. 11. Areas of measurement in the finished product

Table 1. Comparison of measurement of ribs depth according to Figure 11

\begin{tabular}{|c|c|c|c|c|c|c|}
\hline \multirow{2}{*}{$\begin{array}{c}\text { The location of } \\
\text { measurement }\end{array}$} & \multicolumn{2}{|c|}{ Part 1 } & \multicolumn{2}{c|}{ Part 2 } & \multicolumn{2}{c|}{ Part 3 } \\
\cline { 2 - 7 } & piece no. 1 & piece no. 2 & piece no. 3 & piece no. 4 & piece no. 5 & piece no. 6 \\
\hline 1 & 2.57 & 2.58 & 2.58 & 2.56 & 2.56 & 2.57 \\
\hline 2 & 2.56 & 2.60 & 2.59 & 2.58 & 2.59 & 2.60 \\
\hline 3 & 2.57 & 2.59 & 2.58 & 2.59 & 2.59 & 2.59 \\
\hline 4 & 2.57 & 2.57 & 2.58 & 2.58 & 2.57 & 2.57 \\
\hline 5 & 2.58 & 2.60 & 2.59 & 2.61 & 2.58 & 2.59 \\
\hline 6 & 2.60 & 2.58 & 2.59 & 2.58 & 2.57 & 2.58 \\
\hline 7 & 2.59 & 2.58 & 2.57 & 2.59 & 2.58 & 2.57 \\
\hline 8 & 2.57 & 2.57 & 2.58 & 2.58 & 2.57 & 2.58 \\
\hline 9 & 2.60 & 2.61 & 2.60 & 2.61 & 2.58 & 2.59 \\
\hline 10 & 2.60 & 2.58 & 2.59 & 2.58 & 2.57 & 2.58 \\
\hline 11 & 2.57 & 2.58 & 2.58 & 2.56 & 2.56 & 2.57 \\
\hline 12 & 2.56 & 2.58 & 2.59 & 2.58 & 2.59 & 2.58 \\
\hline 13 & 2.59 & 2.60 & 2.59 & 2.61 & 2.58 & 2.59 \\
\hline 14 & 2.58 & 2.57 & 2.58 & 2.58 & 2.57 & 2.58 \\
\hline 15 & 2.57 & 2.60 & 2.58 & 2.59 & 2.58 & 2.60 \\
\hline 16 & 2.56 & 2.59 & 2.59 & 2.59 & 2.59 & 2.59 \\
\hline 17 & 2.56 & 2.58 & 2.59 & 2.58 & 2.59 & 2.58 \\
\hline 18 & 2.57 & 2.59 & 2.58 & 2.59 & 2.58 & 2.69 \\
\hline
\end{tabular}

AW139. Due to similar construction of these elements in all helicopters manufactured by this consortium (certificate requirements), it is planned to widen scope of application of the presented solution to further elements stamped from titanium and aluminum alloys. Obtaining the product in accordance with requirements do not eliminate the problem of undesired deformations of drawpiece. In order to improve the products quality and eliminate the necessity of hand-made straightening, the further tests and research will be carried out aiming at developing stamping technology of sheet products with ribs by means of flexible tools.

\section{REFERENCES}

1. Tekkaya A.E., Taylan A. Sheet metal forming. Processes and applications. Materials Park, ASM International, Ohio 2012.

2. Minghua Z., Qiang X.Y., Yu L., Wenliang C. Prediction algorithm of blank shape for rubber forming of aircraft sheet metal part. AIP Conference Proc. 22.8.2011, Vol. 1383, Iss. 1, 2011, 943-947.

3. Vilcans J., Torims T. Thin sheet metal stamping with elastic media. Annals of DAAAM \& Proc. of the $21^{\text {st }}$ DAAAM Symposium, Croatia, Zadar, (20-23.10.2010), 2010, 849-850.

4. Standards JAR/FAR 29.

5. Company standard Agusta Westland No 999-0010-08. 